\title{
Écfrase, cinema e filosofia: o "poder transme- dial" dos conceitos em Um teste de resistores, de Marília Garcia
}

Resumo: Este artigo parte da análise de poemas ecfrásticos de Marília Garcia, poeta contemporânea brasileira, criados a partir de obras cinematográficas. Partindo da noção de que há, na poesia de Garcia, uma abordagem transmedial dos conceitos - ideia trabalhada por Joana Matos Frias em “'Tudo o que em mim pensa está filmando': pertença e repetição na poesia brasileira contemporânea" (2016) - explora-se a ideia de que a écfrase, na obra em questão, surge como forma de análise crítica das obras fílmicas descritas. Esta abordagem sugere um fazer poético que também é exercício de reflexão sobre as formas de criação artística, situando o eu-poeta numa dupla condição de estar em contato com a obra de arte tanto na condição de espectador e receptor quanto de produtor de reflexões críticas através do próprio fazer poético.

Palavras-chave: Marília Garcia, poesia brasileira contemporânea, ekphrasis, transmedialidade, poesia e cinema

Abstract: This article analyzes the ekphrastic poems of the contemporary Brazilian poet Marília Garcia, created from cinematographic works. Considering the transmedial approach of concepts in Garcia's poetry - idea introduced by Joana Matos Frias in the article "'Tudo o que em mim pensa está filmando': pertença e repetição na poesia brasileira contemporânea” (2016) - this article explores the idea that the ekphrasis, in her work, appears as a form of critical analysis of the movies described. This approach suggests a poetic practice that is also an exercise in critical reflection, placing the self-poet in a double condition when in contact with the work of art, as a spectator and receiver and also as a producer of critical reflections through poetic making itself.

Keywords: Marília Garcia, contemporary Brazilian poetry, ekphrasis, transmediality, poetry and cinema

\section{Introdução}

É notável a intensidade com que o universo cinematográfico é evocado na obra poética de Marília Garcia, desde Câmera Lenta, título de um de seus livros, passando pelas citações diretas a cineastas (como Jean-Luc Godard e Chris Marker) e filmes no corpo de seus poemas. No entanto, sua poesia oferece muito mais do que um simples referencial 
temático ancorado na arte cinematográfica, apresentando, por meio da forma de seus poemas e livros, um complexo conjunto de camadas de sentido construídas a partir das potenciais relações que estabelecem entre poesia e cinema.

A composição dessas diversas camadas tem por base processos reflexivos em torno do próprio fazer poético, do fazer artístico e da criação de imagens. Nesse sentido, fazer poesia e pensar poesia apresentam-se, na obra da autora, como atividades que não se dissociam e a criação artística é em si mesma, enquanto prática, também espaço de reflexão e construção do pensamento. Por essa razão, muitos dos poemas de Marília Garcia não escondem seus referenciais teóricos e artísticos: são eles mesmos a matéria de sua poesia e são não só tematizados de maneira direta e literal mas têm suas formas e modos estéticos incorporados na obra da autora.

Este movimento de apropriação/reflexão aponta para um duplo posicionamento do eu-poeta: tem-se, simultaneamente o eu espectador, que se coloca numa posição de contato e recepção das obras; e o eu pensador que assume uma postura crítico-reflexiva diante das obras artísticas que acessa. Esse movimento pode ser observado especificamente em Um teste de resistores (Garcia 2016), como aponta Joana Matos Frias:

Neste sentido, há no livro de Marília Garcia, um movimento poético reflexivo que transita da problematização teórica para o contato empírico com as obras, e que se exerce sobre várias expressões artísticas em simultâneo, com especial atenção à poesia e ao cinema. (2016: 150)

Por essa razão, compreende-se a existência de uma dimensão cinematográfica na escrita de Marília Garcia na medida em que há a emulação de técnicas e conceitos tradicionalmente reconhecidos no campo do fazer cinematográfico - como a ideia de corte e repetição, presente de forma intensa no livro supracitado. No entanto, mais do que somente "importar" conceitos e técnicas presentes, tanto no universo teórico como no universo prático do cinema, a poesia de Marília Garcia confere a esses conceitos "estatuto de transmedialidade" (ibidem).

A noção de um estatuto de transmedialidade refere-se a "uma leitura intertextual e intermedial" (idem: 148) da poética de Marília Garcia - inserida no contexto da poesia brasileira contemporânea do século XXI - "a fim de reconstituir em que medida a comparência relativamente insistente nelas do domínio cinematográfico e do discurso fílmico ou metafílmico tem servido um propósito mais vasto de reflexão transversal sobre a estrutura do campo artístico" (ibidem).

Assim, deve-se considerar que este estatuto de transmedialidade é traço característico desta poesia, de modo que as análises e reflexões críticas elaboradas a partir da obra da autora levem em conta essa dimensão. Da mesma maneira há que se observar o duplo regime no qual se insere o eu-poeta: ora uma postura crítico-reflexiva, ora uma abordagem sensível-receptiva.

Nas próximas páginas deste artigo serão analisados alguns poemas específicos 
de Marília Garcia, dentre eles alguns os quais Joana Matos Frias identifica como sendo "exercícios ecfrásticos" (2015: 136; 2016: 160). Buscar-se-á observar como as características e regimes apontados acima podem ser identificados em poemas que fazem referências diretas a obras audiovisuais e ao universo técnico do cinema e quais camadas de relações transmediáticas podem surgir quando do encontro dessas duas formas artísticas, a saber, poesia e cinema.

\section{Os conceitos como matéria poética transmedial}

Em seu texto "A new look at an old topic: ekhphrasis revisited", Claus Clüver (2017) propõe uma definição para a écfrase moderna que se distancia de uma ideia de transposição midiática baseada em diferenças fundamentais de modos de representação - verbal e visual - e vai em direção a uma concepção da écfrase como um modo de acessar e refletir a imagem, para além das concepções que circundam a ideia de representação dentro do conceito de arte:

My new definition avoided the ambiguous term "visual representation" and also opened the concept beyond Heffernan's restriction to "a literary representation of visual art" (Heffernan 1993: 1). It promoted the view of ekphrasis as representing a medial configuration as such, as primarily a representation of the image, not of what the image refers to in the extra-artistic world. The verbal texts would not have to be literary, and the objects represented could be "non-representational" paintings or sculptures and even architectural structures; they would have to be medial compositions but not necessarily "art". This reorientation removed the traditional focus on the visual and the verbal as rivaling enterprises engaged in a paragone. (Clüver 2017: 32)

Essa concepção de Clüver a respeito da écfrase ${ }^{1}$ é particularmente eficiente para pensar os exercícios ecfrásticos de Marília Garcia, pois traz a dimensão de transmedialidade para uma técnica (a écfrase) que antes era compreendida como um recurso poético que pensava a representação visual e a representação verbal como essencialmente distintas. A ideia de representação baseada em tipos diferentes de arte dá lugar à noção de "configuração medial" na qual uma perspectiva de transbordamento das fronteiras entre mídias ganha terreno. Esta abordagem vai ao encontro do "estatuto de transmedialidade" já identificado por Frias (2016: 150) na poesia de Marília Garcia.

Observemos, então, como essas perspectivas podem se manifestar no poema de número 1, que compõe o conjunto "Blind light", e abre o livro Um teste de resistores:

no filme pierrot le fou de jean-luc godard

tem uma cena em que os amantes ferdinand e marianne estão fugindo em um carro conversível vermelho por uma estrada ensolarada 
no litoral sul da

frança

nesta cena de pierrot le fou

a câmera filma os dois a partir do banco de trás do carro

nesta cena de pierrot le fou

o ponto de vista do espectador é de quem está de fora

porque os dois estão de costas para a câmera

apesar disso a estrada vai se abrindo à frente

e o movimento carrega todo mundo pra dentro da história

nesta cena de pierrot le fou

o diálogo que ocorre entre ferdinand e marianne

tem um tom bastante leve

para a gravidade do assunto

eles discutem o que farão agora

depois de fugirem juntos depois que ele largou mulher e filha

depois de se envolverem com tráfico de armas

com um assassinato e de roubarem esse carro

ferdinand quer parar em alguma praia tranquila

e ficar com marianne por um tempo

ferdinand diz mais de uma vez que está apaixonado

mas marianne responde que eles precisam de dinheiro

ela sugere que procurem seu irmão para conseguirem grana

e poderem ir para um hotel chique se divertir

nesse momento ferdinand se vira

olhando para trás na direção da câmera

e diz - estão vendo

ela só pensa em se divertir

marianne se vira também olhando para trás

na direção da câmera

e pergunta para ele - com quem você está falando?

ao que ele responde - com o espectador

esse curto diálogo de pierrot le fou

contribui para dar ao filme sua dimensão de filme

de algum modo essa menção ao espectador

fura o filme e insere nele uma espécie de

corte

interrupção que dá a ver mais concretamente 


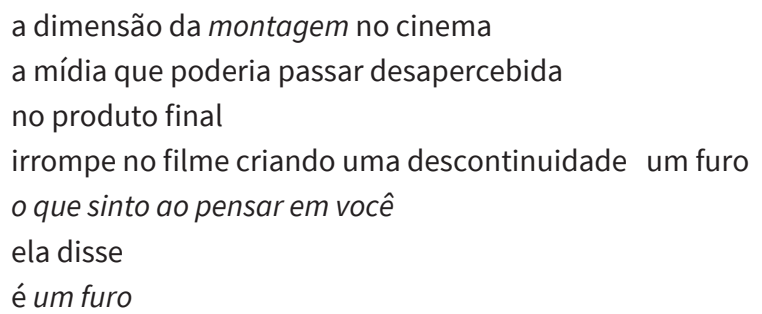

Neste poema é possível observar o duplo aspecto ressaltado por Frias de trânsito entre uma "problematização teórica e o contato empírico com a obra" (2016: 150): ao mesmo tempo em que um procedimento ecfrástico descreve de modo poético uma sequência do filme de Jean-luc Godard, essa descrição também faz parte de uma reflexão crítica a respeito do conceito de corte levantada por Garcia para pensar a própria poesia.

Há, então, mais de uma camada de relações entre mídias distintas. Uma primeira relação de intermedialidade direta que é o processo ecfrástico em si - o filme dentro do poema - e outra camada mais complexa que se dá pelo processo crítico-reflexivo engendrado no texto ao empregar o conceito de corte como o elo transmedial entre poesia e cinema.

É possível ainda observar que o conceito de corte e a ideia de interrupção são incorporados não só como tema crítico-reflexivo, mas também formalmente no poema: em alguns versos é possível notar um espaçamento não regular entre algumas palavras dentro de um mesmo verso, principalmente antes de expressões de falas dos personagens e no segundo verso da última estrofe entre "quais recursos" e "ao lado do corte". Esse procedimento que é amplamente explorado ao longo do livro tende a produzir um efeito prático de corte, de interrupção na escrita e na leitura:

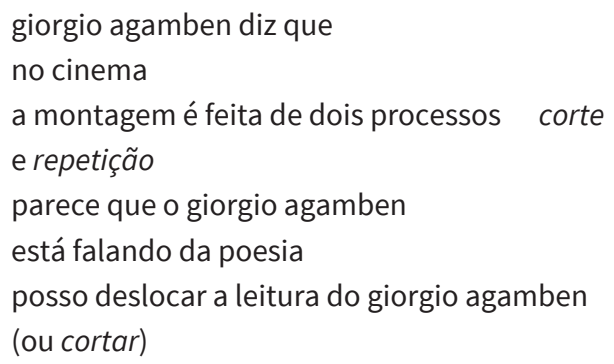




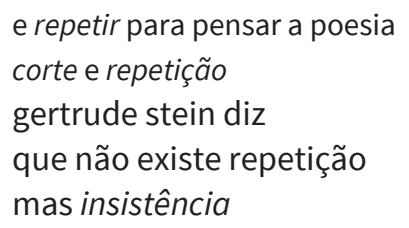

(Garcia 2016: 16)

Esse movimento de abordar um conceito a partir do cinema e deslocá-lo para a poesia "parece propor [...] a eleição dos conceitos de corte e repetição a um estatuto transmedial que propicie a sua utilização pertinente face a diversos objectos estéticos, oriundos de diferentes práticas criativas [...]" (Frias 2016: 150).

Considerando a presença deste estatuto transmedial dos conceitos, é importante observar que no poema em questão há uma transgressão de como o conceito de corte é tradicionalmente utilizado no cinema. Tanto numa perspectiva teórica quanto técnica, quando se fala em corte no cinema fala-se, por um lado, da interrupção da imagem, e por outro, da junção entre um plano e outro. O corte é um procedimento técnico - literalmente cortar o rolo de filme e emendá-lo ou fazê-lo digitalmente - que aparece, para o espectador, como uma interrupção no fluxo da imagem em movimento, "uma mudança instantânea de um enquadramento para outro" (Bordwell/Thompson 2013: 744). No cinema narrativo clássico a técnica da montagem cinematográfica baseia-se justamente em tornar os cortes o mais imperceptíveis possível para o espectador de modo que este se mantenha imerso na narrativa.

No poema de Garcia, o conceito de corte é utilizado para descrever um procedimento estético-narrativo do filme - o personagem que fala com o espectador - que não corresponde ao que tradicionalmente entende-se por corte no cinema, mas que provoca no espectador um efeito análogo ao do corte: a quebra da quarta parede, a interrupção da catarse que sustenta o ato de espectatorialidade no cinema narrativo clássico. E notadamente é Jean-Luc Godard um dos cineastas pioneiros a utilizar o corte de modo descontínuo através do recurso do jump cut ${ }^{2}$ dando a ver "mais concretamente a dimensão da montagem no cinema”, conferindo "ao filme sua dimensão de filme” (Garcia 2016: 15).

O fazer cinema de Godard, que coloca em evidência o próprio aparato técnico cinematográfico e também situa a presença do espectador como parte da experiência fílmica, se aproxima muito do fazer poético de Garcia de modo que é possível observar uma afinidade estética e formal entre a poeta e o cineasta no que concerne uma abordagem transgressora e problematizadora das tradições e limites de seus meios de criação artística.

E, ainda que a poeta transgrida o uso tradicional do conceito de corte para elaborar um comentário crítico do filme de Godard ela não o afasta totalmente de seu significado. O corte é destituído de seu significante material que o caracteriza como um conceito "de cinema”, mas mantém seu efeito no nível da percepção do espectador, sugerindo 
assim que o efeito deste recurso técnico pode ser alcançado através de diferentes procedimentos estético-formais, não só no cinema, mas também na poesia. Desse modo "o que esta obra propõe é justamente o nomadismo dos conceitos como forma mesma da sua existência, sem que se restabeleça esse momento em que eles teriam sido formas específicas de um único medium" (Frias 2016: 150).

Percebe-se, então, que há a expressão de uma imagem de pensamento bastante complexa que se estabelece no fundo da sua obra, como que costurando os poemas do livro e conferindo-lhe uma unidade de pensamento crítico. Para o filósofo Gilles Deleuze "a filosofia consiste sempre em inventar conceitos" (1992: 170) e nesse sentido podemos identificar uma "pulsão filosófica" (Heringer 2016: s/p) na poesia de Marília Garcia ao efetuar uma ressignificação dos conceitos conferindo-lhes novas potencialidades.

No entanto, ainda que suponhamos um desejo filosófico na obra de Garcia o livro em questão é, ainda e sobretudo, um livro de poemas. Um livro que, justamente por seu estatuto de transmedialidade, estabelece uma relação com o cinema que vai além da tematização e "tem consequências mais profundas porque diz respeito à cumplicidade entre duas artes que partilham uma extensa e multímoda reflexão sobre os processos de fazer imagem" (Martelo 2012: 12).

Temos, portanto, a eleição de conceitos (domínio da filosofia) - como o "corte" e "repetição", ${ }^{3}$ além de outros como "tempo" e "espaço" que surgem ao longo do livro - como matéria da própria criação poética. E, para Deleuze, "o conceito [...] comporta duas outras dimensões, as do percepto e do afecto.” (Deleuze 1992: 171).

Assim, é possível compreender que é a "reflexão dos processos de fazer imagem" (Martelo 2012: 12), que compete tanto ao cinema quanto à poesia, o que impulsiona o estatuto de transmedialidade que Frias identifica na poesia de Marília Garcia. Uma poesia que partiria da ideia de que os modos de criação de imagens na contemporaneidade não são específicos ou exclusivos de determinados meios ou categorias artísticas, e é por meio da reflexão crítica e da ressignificação de conceitos que se dá o ato da criação poética, na medida em que estes derivam dos perceptos e dos afectos que sobrevivem aos acontecimentos:

Os perceptos não são percepções, são pacotes de sensações e de relações que sobrevivem àqueles que os vivenciam. Os afectos não são sentimentos, são devires que transbordam aquele que passa por eles (tornando-se outro). [...] O afecto, o percepto e o conceito são três potências inseparáveis, potências que vão da arte à filosofia e vice-versa. (Deleuze 1992: 171)

O exercício ecfrástico a partir do filme de Jean-Luc Godard pode ser compreendido como a prática deste programa deleuziano da potência de criação baseada na tríade afecto-percepto-conceito. O poema como resultado da experiência vivida, como desdobramento do acontecimento. O que sobra depois que se assiste a um filme? O que se transforma? O que fica na memória e o que pode ser criado a partir da experiência de um 
acontecimento? E quando esse acontecimento é o contato com uma obra de arte? Com um filme?

Nesse esquema, é possível desenhar um percurso que começa com a recepção da obra fílmica e se conclui com a produção do poema (na prática a conclusão se dá no momento da leitura do poema, mas aqui estamos pensando o esquema da produção da obra em si). É possível, então, pensar que o filme (o cinema) atue, no caso da poesia de Garcia, como um disparador do que Paul Valéry chama de estado poético:

Eu a reconheço em mim [a emoção poética] nesta característica de que todos os objetos possíveis do mundo comum, externo ou interno, os seres, os acontecimentos, os sentimentos e os atos, permanecendo o que são normalmente quanto à suas aparências, encontram-se de repente em uma relação indefinível mas maravilhosamente ajustadas ao gosto de nossa sensibilidade geral. Isso significa que as coisas e esses seres conhecidos - ou melhor, as idéias que os representam - transformam-se em algum tipo de valor. Eles se chamam entre si, associam-se de forma completamente diferente da dos meios normais; acham-se (permitam-me esta expressão) musicalizados, tendo se tornado ressonantes um pelo outro e como que harmonicamente correspondentes. (Valéry 1991: 197)

O estado poético seria esse acontecimento muito específico que induz a certo estado de espírito, que ressoa determinadas sensações e sentimentos (afectos e perceptos) a partir da apreensão do mundo. Ora, o estado poético, compreendido nesses termos vai ao encontro do esquema deleuziano da potência criadora fundada no afecto-percepto-conceito. No entanto, como destacou Valéry, entre o estado poético e a criação de uma obra poética em si há uma diferença (1991: 199). E aí entra o trabalho de pensamento da linguagem, a reflexão, que no esquema deleuziano corresponderia ao terceiro polo, o conceito. ${ }^{4}$

Em seu ensaio "Poesia e pensamento abstrato" o que Valéry propõe é justamente reconhecer as capacidades de raciocínio e pensamento abstrato do poeta como procedimentos essenciais ao ato da criação poética. "O poeta tem seu pensamento abstrato e, se quisermos, sua filosofia: e disse que ele se exercia em seu próprio ato de poeta” (1991: 208). E por auto-observação, Valéry constatou que o ato de criação do poeta exigia "não apenas aquela presença do universo poético do qual falei, mas também uma quantidade de reflexões, de decisões, de escolhas e combinações sem as quais todos os dons possíveis da Musa ou do Acaso continuariam sendo materiais preciosos em um canteiro de obras sem arquiteto" (ibidem).

Para Valéry o poema é uma "máquina de produzir o estado poético a partir das palavras" (1991: 209). Logo, os poemas de Um teste de resistores podem ser compreendidos como uma maneira de produzir o estado poético a partir da experiência mesma da espectatorialidade fílmica que, inicialmente, foi catalizadora do estado poético. Pois, se o estado poético pode levar o poeta à criação do poema, este, por sua vez, pode produzir 
no leitor também o acontecimento do estado poético. Tem-se, na forma de circuito, a comunhão da experiência do estado poético por quem produz o poema e por quem o lê. Em Um teste de resistores há, então, não somente o poema como registro da experiência de ser espectador de cinema, mas como exercício de reinvenção do acontecimento em si.

Se os afectos e os perceptos que, junto aos conceitos, criam as condições da criação poética e do pensamento filosófico - é nessa triangulação conceito-afecto-percepto que orbita a poesia de Marília Garcia, operando nesse circuito que transporta o estado poético de si para o leitor.

Mas o estado poético que o poema produz no leitor nunca é idêntico ao que o poeta experimentou. Então, mais do que transportar, há uma conversão do estado poético original que para cada leitor aparece como algo novo cada vez que o poema é lido. A ideia de poesia como um teste de resistores faz todo sentido, pois o resistor (ou a resistência) é justamente esse dispositivo capaz de converter um tipo de energia em outra (energia elétrica em energia térmica, no caso do chuveiro que é a situação a qual Garcia se refere no livro).

Garcia mostra, em Um teste de resistores, que o cinema pode ser um acontecimento capaz de mobilizar os afectos e os perceptos e converter o estado poético em obra poética. E a operação deste movimento recorre à memória. Grande parte dos poemas de Um teste de resistores são exercícios de conversão de acontecimentos em afectos, perceptos e conceitos através da memória. Ou, mais especificamente, a encenação de lembranças como imagem dos afectos e perceptos e os conceitos de corte e repetição, elevados a seu “poder transmedial” (Frias 2016: 155), como técnica de elaboração dos poemas.

Os conceitos de corte e repetição, mais que recursos estético-formais, são, em si mesmos, a expressão poética em Um teste de resistores na medida em aparecem como signos da memória e recursos técnicos da operação poética. A memória que se apresenta não como a lembrança estrita do que foi, mas como uma imagem reinventada, atualizada - "ela [a memória] já não nos representa nosso passado, ela o encena" (Bergson 1999: 89), ${ }^{5}$ uma imagem que se repete, que insiste, que "prolonga seu efeito útil até o momento presente" (Bergson 1999: 89) e atua diretamente na percepção.

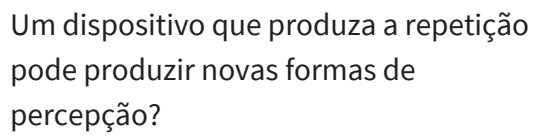

Ora, não seria a memória mesma um dispositivo orgânico de produção de repetição? Como observa Frias (2016: 154), a partir de Giorgio Agamben (cuja filosofia é incorporada no livro de Marília Garcia), é justamente essa dimensão de produção do novo a partir da repetição que está presente no livro: "The force and the grace of repetition, the 
novelty it brings us, is there turn as the possibility of what was" (Agamben 2002: 315). A produção de novas formas de percepção que Garcia experimenta em seu livro é realizada por meio da reflexão crítica transmedial, reconhecendo que as potencialidades da criação não são específicas ou exclusivas de determinadas artes ou meios, e, portanto, que há uma transversalidade nas formas de percepção e criação possibilitadas pelas diferentes artes ou mídias.

É portanto com toda congruência que o lexema "percepção" emerge no final destes versos. Uma vez que neles se problematiza [...] o alcance e as consequências dos procedimentos de corte e de repetição na percepção estética da obra de arte, entendida esta enquanto experiência radical do que poderia ser designado como uma espécie de "pós-montagem". Neste sentido, leitor, espectador e ouvinte associam-se estreitamente nas respectivas experiências porque a experiência de cada um é sempre, de novo nos termos de Agamben, a de restauração da possibilidade do que foi, o que leva esta repetição a aproximar-se da memória em condições análogas às que podem definir a repetição cinematográfica: porque ela se dá, não apenas entre imagens ao nível da produção, mas também ao nível da recepção, no modo como essas imagens se associam na percepção do espectador, e como ficam a ressoar posteriormente na sua memória presentificada [...]. (Frias 2016: 156)

A partir desta analogia seria possível concluir, então, que em Um teste de resistores o cinema funciona como uma dupla metáfora: metáfora da percepção (nível da recepção fílmica), porquanto delimita "o ser espectador de cinema" como esse acontecimento capaz de mobilizar afectos, perceptos e conceitos de modo a produzir algo novo; e metáfora da memória (nível da produção fílmica) na medida em que o filme é fundamentalmente essa operação de montagem e organização de imagens, corte e repetição.

Para Aleida Assmann "o fenômeno da memória é resistente à descrição mais direta e incide em processos metafóricos" (2011: 162) de modo que "as imagens desempenham papel de figuras de pensamento, modelos que demarcam os campos conceituais e orientam as teorias. Por essa razão é que os 'conjuntos de metáforas' nesse campo não são uma linguagem que parafraseia, mas uma linguagem que primeiro desvela o objeto e o constitui" (ibidem).

A metáfora do cinema, neste caso, teria como função construir a imagem desse dispositivo que, por meio da repetição, é capaz de produzir novas formas de percepção e, consequentemente, relacionar-se com a memória. Há uma indissociação entre memória e percepção que seria essencial para elaboração de novas formas de perceber. Desse modo, ao trazer o cinema e seus recursos técnicos para o poema, Garcia não estabelece apenas um meio para tematizar a memória, mas, justamente pelo caráter crítico-reflexivo de sua poesia, empreende experimentações poético-conceituais em torno das experiências contemporâneas da memória e da percepção. 
Experiência e recordação nunca se deixam harmonizar em conformidade plena. Entre ambas há um hiato em que o conteúdo da memória será deslocado, esquecido, obstruído, repotencializado ou reconstruído. Quanto mais as metáforas da memória fazem jus a essa dinâmica imanente das recordações tanto mais elas realçam a dimensão temporal como fator decisivo e tanto mais fazem da reconstrução dos conteúdos da memória o verdadeiro problema em questão. (Assmann 2011: 191)

É nesse sentido que os conceitos de corte e repetição emergem como signos da memória, pois representam as operações pelas quais esta atua, representam as dinâmicas pelas quais a experiência vivida (passado) se atualiza em recordação (presente). Em Um teste de resistores essa experiência é marcada por uma ideia de descontinuidade e pela compreensão do filme como acontecimento que em si mesmo constitui uma experiência poética. O que sobra depois do filme é diferente do filme em si. Novas imagens são criadas de uma memória atravessada pela experiência fílmica, que por sua vez irão produzir no leitor uma nova experiência poética.

É exatamente isso que acontece em Um teste de resistores, de Marília Garcia, porquanto aquilo que no livro comparece dos filmes explicitamente mencionados (destaque-se Pierrot le Fou, de Godard, e La jetée, de Chris Marker), é justamente um restrito conjunto de fragmentos pregnantes ("tem uma cena”, "nesse momento", "há uma única cena”) que por interrupção provocam a descontinuidade do continuum fílmico, instalando-a na percepção e na presentificação do espectador. (Frias 2016: 156)

A escolha de La Jetée (1962), de Chris Marker, também para compor um exercício ecfrástico, não é de modo algum aleatória. O filme, uma fotonovela e também uma ficção científica, trata justamente da memória e da restauração da possibilidade do que foi. Ao trazer esse filme para dentro do poema e descrevê-lo de maneira tão literal Garcia parece explicitar a ideia do cinema como metáfora da memória e da percepção. A percepção como essa operação que ocorre no presente, a cada instante, mas serve-se a todo momento das imagens da memória, da experiência que foi.

o filme la jetée do chrismarker

é todo feito a partir de fotografias imagens fixas

que vão passando pouco a pouco

como um filme antigo

o cinema hoje também é feito de imagens fixas

mas são usadas 24 imagens por segundos

o que produz a ilusão do movimento

no filme de chrismarker

ele usa a mesma imagem por vários segundos 


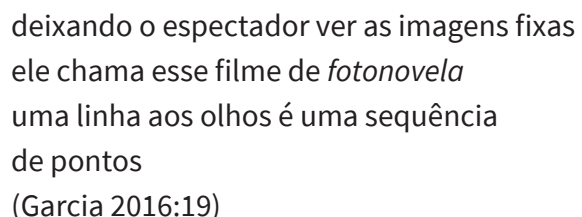

O mesmo filme volta a ser descrito posteriormente no livro, num poema que começa da mesma maneira que o anterior, mas termina de outro modo. Esse movimento de corte e repetição aparece ao longo de todo o livro: também o filme de Godard aparece em mais de um poema, bem como versos e frases que correm de um poema a outro, que se repetem ao longo do livro mas sempre num novo arranjo, numa nova presentificação:

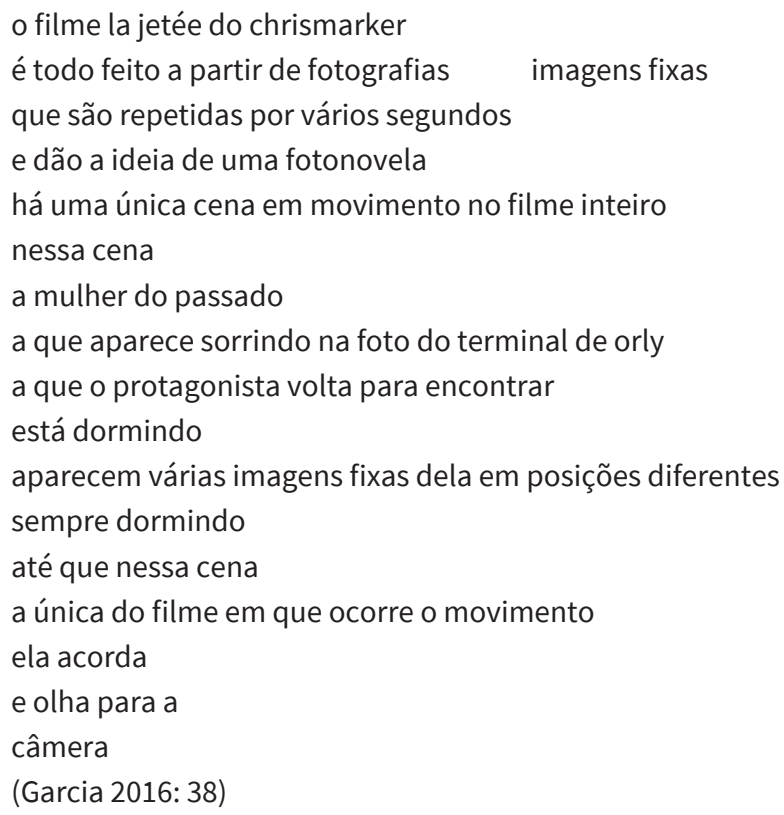

Garcia trabalha com um método que considera a existência de fragmentos - de imagens da memória - disponíveis para serem combinados e reorganizados. Tem-se explicitamente uma ideia de montagem, ancorada na transmedialidade dos conceitos de corte e repetição. Essa noção pode ser percebida nas relações que a autora estabelece entre seus poemas e até mesmo entre seus livros. Por exemplo, há um verso que aparece primeiro no poema "A poesia é uma forma de resistores?" do livro Um teste de resistores: "(...) a poeira da cidade do / méxico deve vir de todos os vasos / que são quebrados na cidade do méxico" (2016: 115). Algumas variações deste mesmo verso aparecem posteriormente no mesmo poema e no poema "hola, spleen" do livro Câmera Lenta (2017: 11). 
Logo, observa-se que não só a poeta traz os conceitos de corte e repetição para a poesia a partir de sua reflexão crítica de obras cinematográficas e textos teóricos, mas também explora as possibilidades estéticas de aplicação desses conceitos. Faz bastante sentido, então, que a palavra teste apareça no título do livro, evocando assim uma ideia da poesia como investigação, como lugar de elaboração crítica. No centro desse processo de teste empregado pela poeta há uma concepção nômade e transmedial dos conceitos, e, ainda, a eleição do conceito enquanto imagem do pensamento capaz de converter-se em imagem poética.

\section{Auto-reflexividade crítica: poesia como experimentação}

A poesia de Um teste de resistores, como dito anteriormente, apresenta muitas camadas de relações, não só com outras artes e mídias, mas também com outros campos do saber, como a filosofia. O modo pelo qual Garcia faz essa operação é apropriando-se do conceito - de conceitos específicos, como corte, repetição, memória, imagem; mas também da ideia de conceito em si - enquanto meio possível de reflexão-criação fortemente associada a um expediente de crítica e desconstrução do fazer artístico que coloca lado a lado poesia e cinema.

Ao trazer a ideia de cinema como metáfora para pensar a poesia de Um teste de resistores deve-se compreender a percepção como uma interface de contato com o mundo: ver o mundo como ver um filme (em nossa cultura contemporânea é possível dizer que há até certa literalidade nesta metáfora, pois de fato boa parte de modo como percebemos o mundo é através das telas dos dispositivos eletrônicos); e a memória, simbolizada pelos mecanismos de corte e repetição, como o meio de operação poética: escrever o poema como quem faz um filme.

A reflexão que se desdobra do contato com o filme resulta em poemas que constroem um pensamento crítico que, simultaneamente, olha para o cinema e para a poesia. Olhar para o cinema é como olhar um espelho e ver nele refletida a poesia ela mesma. A abordagem transmedial dos conceitos em Garcia tem como princípio reconhecer a poesia que há no cinema. Afirmar que o contato com o filme é, antes de tudo, uma experiência poética.

Ainda sobre as metáforas da memória, Assmann afirma que, "se a escrita havia sido interpretada como manifestação do espírito, entendeu-se a imagem, então, como manifestação de um afeto ou do inconsciente" e que seu "potencial afeccional incontrolável, faz desse medium da memória [...] o suporte privilegiado do inconsciente cultural" (2011: 237). Assmann aponta que ao nível fisiológico o processamento de imagens e da linguagem funcionam de modo simultâneo na formação da memória, de modo que essa estrutura intermedial seja responsável pela complexidade e produtividade tanto da memória individual quanto da memória cultural" (ibidem).

A ideia de transmedialidade agora se dirige ao conceito de memória, visto que, ao propor a ambivalência medial dos conceitos de corte e repetição Garcia efetua uma 
aproximação entre escrita e imagem enquanto metáforas da memória. Ela estabelece, assim, o terreno para suas reflexões críticas e para sua prática poética no qual prevalece a ideia de convergência e compartilhamento entre meios e artes, o que pode ser observável não somente no seu expediente crítico-reflexivo mas em como a poeta convoca a presença de diversas vozes e obras para seu livros, constituindo uma rede de referências interartísticas que lhes parecem ser muito caras.

É possível dizer, então, que a reflexão crítica no livro é fundada numa auto-reflexividade que é da ordem do afetivo, do diálogo, do encontro com o outro por meio da arte, da poesia como meio de troca e como meio de experimentar o mundo. Produzindo assim um discurso que "abre espaço para a outridade, permitindo a constatação de que o lugar do outro em cada um de nós e do outro em nós é crucial passo para qualquer reflexão crítica, inclusive porque é a fundação do sentido da poesia, como o é de outras experiências" (Martha 2015: 15).

Essa postura da crítica que pressupõe a outridade parece ter lugar privilegiado na obra de Garcia, talvez por ela ser, antes de tudo, poeta, e por ter a reflexão crítica como meio de sua expressão poética. Desse modo a poesia de Garcia encontra no cinema seu outro e a partir dele constrói "um dizer sobre esse mesmo objeto que é, inevitavelmente, um dizer sobre si, suas crenças, suas preferências, e, ao mesmo tempo, um dizer sobre o tempo e a palavra poética" (Marta 2015: 16).

O termo "diário-crítico-afetivo" que Victor Heringer utiliza para descrever Um teste de resistores no texto de orelha do livro parece sintetizar bem a operação do circuito poético que se estabelece entre receber uma obra (ver um filme) e produzir uma obra (escrever o poema). O contato com outras obras e artistas constitui em si mesmo uma experiência poética para Garcia: o estado poético como evento catalisado pela percepção; e o poema como obra que é testemunho dessa experiência vivida, que é registo dessa da mobilização de afetos causada pelo contato com o cinema e que, por sua vez, contém a potência de ser também uma experiência poética para o leitor.

Assim, Um teste de resistores parece de fato ter a função de diário, de registro e organização de referências que são caras a poeta e pelas quais, em última instância, há um desejo de compartilhamento, de mostrar ao mundo, de fazer ver e tocar ao outro o que inicialmente a poeta pode experimentar quando do contato com essas obras e da vivência dessas experiências. Algo muito semelhante à escrita-pensamento de Paula Glenadel, na qual a atividade de leitura desperta o desejo de autoria (Glenadel 2010: 249). A "escrita como um 'jorro de desejo' impossível de ser contido" (Medeiros 2019: 74), que em Um teste de resistores alcança a transmedialidade, ao passo que é a experiência de ser espectador de cinema que mobiliza o desejo da escrita.

Paula Glenadel inscreve a sua experiência de escrita num duplo sentido de ir para trás e para frente. Ir para trás seria homenagear as leituras feitas. Ir para frente, o impulso criador (2010: 249): 
Para trás e para frente, memória e invenção da memória, a escrita outra torna o estar no mundo um momento sempre já reflexivo, acaba com a pretensão à espontaneidade e reforça o caráter inaugural da experiência literária que, finalmente, aparece como uma instância produtora da experiência de vida, ao ordená-la, interpretá-la, fazê-la significar, e não se limitar a meramente representá-la. (Glenadel 2010: 249)

Talvez Marília Garcia, em Um teste de resistores, queira homenagear os filmes que assistiu, queira falar deles, pois falar deles é também fazer poesia. Por isso a reflexividade, por isso a pulsão filosófica e a reflexão crítica. Pois a representação mostra-se limitadora para a experiência poética contemporânea, seja vivenciando-a como acontecimento seja protagonizando-a como agente da criação.

Entende-se que esse modo de criação pressupõe uma ideia de poesia que avança para além do seu campo, de seus domínios. Pode-se, então, situar a obra de Marília Garcia dentro de uma ideia de arte inespecífica, marcada por "um modo de estar sempre fora de si, fora de um lugar ou de uma categoria próprios" (Garramuño 2014: 8). Assim, um estatuto de transmedialidade estaria intimamente conectado a esta noção de uma arte que transborda seus próprios domínios:

$\mathrm{Na}$ aposta no entrecruzamento de meios e na interdisciplinaridade, é possível observar uma saída da especificidade do meio, do próprio, da propriedade, do enquanto tal de cada uma das disciplinas, uma expansão das linguagens artísticas que desborda os muros e barreiras de contenção. E é importante estudar o percurso desse entrecruzamento como um discurso contra a especificidade do meio porque esse percurso permite desentranhar alguns dos sentidos históricos mais importantes dessa aposta no inespecífico na arte contemporânea. (idem: 10)

Nesse modo de estar fora de si, Garcia efetua, em Um teste de resistores, um experimento poético que transita entre os campos da filosofia e do cinema e compõe uma obra que abarca, simultaneamente, a reflexão crítica, o relato pessoal, o diário de viagem, o caderno de anotações:

Não somente a resistência, como também a escrita de Marília se coloca em teste quando, por exemplo, é construída como um caderno de anotações. Ao forçar os limites do que seria característico ou específico do literário - através da articulação de citações próprias ou de escritores e filmes que lhe são caros, comentários e críticas pessoais e até mesmo a narrativa de seu cotidiano -, Um teste de resistores parece nos fazer atentar de capítulo em capítulo, ao quase nos rendermos à descrença desta escrita como poesia, ao fato de que tudo nela é ensaio, experimento. (Reis 2015: 289)

Quem lê o livro acessa um grande número de referências artísticas e teóricas - Hilary 
Kaplan, Giorgio Agamben, Wislawa Szymborska, Roberto Bolaño, Gertrude Stein, Chris Marker, Jean-Luc Godard. Acessa também lugares visitados, de museus a aeroportos e cidades, além dos interlocutores da poeta, artistas e teóricos.

Tudo parece fazer parte de um "espírito de anotação" (Garramuño 2014: 10) e de uma "rede de discursos e de imagens, uma rede de pensamento da qual fazem parte diversas vozes, diversas máscaras, diversos personagens" (Medeiros 2019: 70) que inserem a obra efetivamente num estatuto transmedial na medida em que, ainda que a obra em si seja o livro físico, todas as referências estão lá, descritas, teorizadas, traduzidas, problematizadas de modo que se apresentam como extensões e fundamentos do livro em si.

Observa-se, então, a noção já apontada anteriormente da presença de um duplo eu-poeta: um que absorve, coleta, lê, assiste, acessa, é espectador; e outro que produz, cria, reflete, teoriza, critica. A fronteira entre eles, claro, é difusa e com frequência eles se confundem e, no contexto desta obra específica, um não existiria sem o outro. Esta noção está presente de modo semelhante em Paula Glenadel cuja "escrita [...] faz-se entre o fluxo do que contaminou o leitor e o jorro do desejo de se tornar autor" e leva a noção de uma escrita não-criativa na qual "a reinvenção da criatividade significa propor a leitura como uma espécie de escrita” (Azevedo 2017: 163).

Essa dupla dimensão fica particularmente evidente na relação que Garcia estabelece com o cinema e ao mesmo tempo situa essa postura num regime de transmedialidade: ela é espectadora e a experiência do cinema lhe provoca grande impacto enquanto experiência poética. Esta experiência estimula a produção de reflexões críticas, confronta o cinema com a poesia, evidencia sua inespecificidade, pois, num contexto contemporâneo em que as obras "parecem compartilhar um mesmo desconforto em face de qualquer definição específica ou categoria de pertencimento em que instalar-se" (Garramuño 2014: 7) os limites e padrões de autoria e identidade do sujeito que cria também passam a ser revirados por dentro.

\section{Conclusão}

Para Garramuño, a "aposta no inespecífico seria um modo de elaborar uma linguagem do comum que propiciasse modos diversos do não pertencimento. Não pertencimento à especificidade de uma arte em particular mas também, e sobretudo, não pertencimento a uma ideia de arte como específica" (idem: 11). Logo, junto a uma prática de desconstrução de padrões e paradigmas estabelecidos dentro das artes e meios há uma mudança de percepção do que pode ou não ser chamado de arte, ou, ainda, do que se pode ou não ser estabelecido e atribuído ao que tradicionalmente entende-se como arte.

Partindo dessa proposta é bastante coerente que Marília Garcia compreenda a própria obra como experimento, como "teste" e incorpore na criação uma auto-reflexividade crítica que estabelece a "contradição metalingüística de estar dentro e fora, de 
ser cúmplice e distante, de registrar e contestar suas próprias formulações provisórias" (Hutcheon 1991: 41).

Um teste de resistores aponta para a possibilidade de que a reflexão crítica, a problematização de conceitos, a citação, a anotação possam ser tomados como material de poesia. Ou, ainda, possam ser, eles mesmos, a materialização de uma obra poética. Nos poemas tratados nesse artigo observa-se o uso da écfrase vinculada a uma possibilidade de reflexão e a práticas que podem ser identificadas com as da filosofia, anotação e produção crítica. No "diário crítico-afetivo" de Garcia as ideias de inespecificidade dos meios, transmedialidade dos conceitos e auto-reflexividade crítica são, a um só tempo, regimes que atravessam seu modo de fazer poético porquanto surgem no exterior das práticas poéticas em si; mas também constituem estatutos de criação que se criam e desenvolvem dentro de sua obra a partir das necessidades de sua expressão poética.

Esse estar "dentro e fora" dos regimes imanentes da criação artística do seu tempo possibilita enxergar a própria obra como teste, como constante experimentação de si mesma numa tentativa de estabelecer uma nova relação com a linguagem. O resultado é sempre a poesia possível. Possível no contexto contemporâneo de uma arte não específica, no regime de transmedialidade, na ideia de arte não criativa. Nesse cenário a poesia se situa cada vez mais como uma prática que se mescla e se confunde a outros modos de fazer da vida que não são tradicionalmente reconhecidos como pertencentes ao campo artístico.

\section{NOTAS}

\footnotetext{
* Yasmin Bidim Pereira dos Santos é doutoranda em Estudos de Literatura pela Universidade Federal de São Carlos, São Paulo, Brasil. Possui graduação e mestrado em Imagem e Som pela mesma universidade. É professora do curso de Especialização em Educação e Tecnologias da UFSCar. Também é produtora cultural, poeta e artista multimídia. Autora dos livros Rota das Raízes: Gastronomia e Cultura no Estado de São Paulo (ProAc, 2018) e Livro dos Interiores (poesia, Penalux, 2010).
} 
${ }^{1}$ Ainda que o texto de Clüver traga a definição de écfrase moderna para descrever apenas o encontro com configurações visuais não-cinéticas - "Ekphrasis verbalizes a real or fictive viewer's perceptions of, or reactions to, characteristic features of non-kinetic visual configuration" (Clüver 2017: 41) - o que, em tese, excluiria o cinema. Entendemos que, para as reflexões desse artigo, a ideia de transmedialidade trazida por ele vai ao encontro das reflexões de Joana Matos Frias a respeito da obra de Marília Garcia. Assim, a definição de Clüver nos parece bastante útil para pensar esses exercícios ecfrástico de Marília Garcia na medida em que há a convergência de um pensamento teórico entre os dois autores acima citados no que diz respeito a um estatuto transmedial da écfrase.

2 Sobre o recurso do jum pcut em Godard:

"Em Acossado (À bout de souffle), Jean-Luc Godard viola convenções da continuidade espacial, temporal e gráfica por meio do uso sistemático do jumpcut [falso racord, salto]. Apesar de frequentemente usado sem rigor, o significado primário da designação é este: quando dois planos do mesmo tema são unidos, mas não são suficientemente diferentes em distância e em ângulo de câmera, haverá um salto perceptível na tela. [...] Longe de fluírem sem ser percebidos, tais cortes são muito visíveis" (Bordwell/Thompson 2013: 395)

${ }^{3}$ Percebe-se aqui que, embora o corte e a repetição sejam procedimentos técnicos e estéticos de domínio do fazer cinematográfico, no livro de Garcia eles são alçados à categoria de conceitos, são problematizados, teorizados, recebem um tratamento crítico que os fazem migrar do domínio técnico para o domínio do pensamento, da prática filosófica.

${ }^{4}$ Importante ressaltar aqui que não estamos reduzindo as reflexões teóricas de Valéry ao esquema deleuziano do conceito, mas propondo uma maneira de interpretar este pensamento a respeito da criação poética sob uma ótica que destaca justamente a ideia de conceito que parece ser bastante relevante na poesia de Marília Garcia.

${ }^{5}$ Em Matéria e Memória, Henry Bergson descreve dois tipos de memória: uma que registra, "sob forma de imagens-lembranças, todos os acontecimentos de nossa vida cotidiana à medida que se desenrolam" (1999: 88-89), a qual ele descreve como uma memória que imagina; e outra que ao invés de conservar imagens antigas "prolonga seu efeito útil até o momento presente". Este segundo tipo ele caracteriza como uma memória que repete (ibidem). 


\section{BIBLIOGRAFIA}

Antelo, Assmann, Aleida (2011), Espaços da Recordação. Formas e transformações da memória cultural, Campinas, Editora Unicamp.

Agamben, Giorgio (2002), "Difference and Repetition: on Guy Debord's Films”, in Guy Debord and the Situationist International, Cambridge, Mass., MIT Press.

Azevedo, Luciene (2017), "Romances não criativos”, Estud. Lit. Bras. Contemp., n. 50, Brasília, 157-171.

Bergson Henri (2006), Matéria e Memória, tradução de Paulo Neves, São Paulo, Martins Fontes.

Bordwell, David / Thompson, Kristin (2013), A Arte do Cinema: uma introdução, Campinas/ São Paulo, Editora Unicamp e Editora USP.

Clüver, Claus (2017), "A new look at an old topic: ekphrasis revisited". Todas as letras, São Paulo, v. 19, n. 1, 30-44.

Deleuze, Gilles (1992), Conversações, tradução de Peter Pál Pelbart, São Paulo, Editora 34.

Frias, Joana Matos (2015), "O corpo em câmera lenta caindo (depois do filme fez um poema)", in A Escrita do Cinema: Ensaios, Lisboa, Documenta.

-- (2016), “'Tudo o que em mim pensa está filmando"”: pertença e repetição na poesia brasileira contemporânea", Relâmpago, n. 38, 147 - 165.

Garcia, Marília (2016), Um teste de resistores, Rio de Janeiro, 7 Letras.

Garramuño, Florencia (2014), Frutos estranhos: sobre a inespecificidade na arte contemporânea, Rio de Janeiro, Rocco. [Edição Digital]

Glenadel, Paula (2010), “Mais Um no Oceano”, Remate de Males, vol. 30, no 2, 247-251.

Heringer, Victor (2016), in Garcia, Marília, Um teste de resistores, Rio de Janeiro, 7 Letras. [Orelha do Livro]

Hutcheon, Linda (1991), Poéticas do Pós-modernismo, Rio de Janeiro, Imago.

Martelo, Rosa Maria (2012), O cinema da poesia, Lisboa, Documenta.

Marta, Diana Junkes Bueno (2015), "Poesia e Crítica: Por uma leitura intervalar em defesa do leitor sitiado", Revista do Gel, v. 12, n² 2, 11-29. <https://revistas.gel.org.br/ $\mathrm{rg} / \mathrm{article} / \mathrm{view} / 266 / 433>$ (último acesso em 20/07/2020)

Medeiros, Manuela Quadra de (2019), "A escrita em rede de Paula Glenadel”, Elyra, n 13, 69-94. <http://dx.doi.org/10.21747/21828954/ely13a4> (último acesso em 18/07/2020)

REIS, Julya Tavares (2015). "A Palavra Iminente de Marília Garcia”, in Seminário dos Alunos dos Programas de Pós-Graduação do Instituto de Letras da UFF, n 6, Niterói. UFF. <http://www.anaisdosappil.uff.br/index.php/VISAPPIL-Lit/article/ view/369/209> (último acesso em 18/07/2020)

Valéry, Paul (1991), “Poesia e Pensamento abstrato”, in Variedades, São Paulo, Iluminuras. 